\title{
Development of Colonic Necrosis Following Severe Acute Pancreatitis
}

\author{
Yoshikazu Umeno, Junji Otsuka, Eizaburo SASATomI* and Koji IRIE*
}

\begin{abstract}
We herein describe a 70-year-old male patient who developed colonic necrosis following severe acute pancreatitis. He was referred to our hospital with a diagnosis of acute pancreatitis. In the course of the disease, he developed sudden and massive hematochezia and died. The autopsy findings revealed large bowel ischemia with transmural infarction. The possible pathogenic mechanisms of colonic ischemia are also discussed.
\end{abstract}

(Internal Medicine 39: 305-308, 2000)

Key words: pancreatitis, colonic complication, pathogenesis

\section{Introduction}

Colonic involvement is an uncommon but potentially lethal complication of acute pancreatitis. It has been estimated that $1 \%$ of the patients with acute pancreatitis develop colonic complications (1-4). Such accompanying lesions show a wide spectrum, including functional ileus, mechanical ileus due to surrounding compression, ischemic necrosis, and fistula formation. The most common manifestation is colonic ileus, which can be seen as the "colon cut-off" sign on plain abdominal film. Necrosis of the colon rarely complicates acute pancreatitis $(4,5)$. In this article, we report a patient with acute pancreatitis who developed serious colonic necrosis.

For editorial comment, see p 275.

\section{Case Report}

A 70-year-old man suffered from sudden epigastralgia after eating breakfast on April 3, 1998. His past history was unremarkable except for a two-year history of atrial fibrillation with no medication. He had no history of alcohol abuse. The pain gradually worsened with accompanying symptoms such as nausea and vomiting, and he was admitted to a local hospital. The laboratory findings at admission were normal except for an elevation of pancreatic enzymes. At two days after the onset of symptoms, however, the white blood cell count was 9,200/ $\mu \mathrm{l}$, red blood cell count $470 \times 10^{4} / \mu \mathrm{l}$, hemoglobin $15.1 \mathrm{~g} / \mathrm{dl}$, platelet count $8.7 \times 10^{4} / \mu 1$, amylase $187 \mathrm{IU} / l$, blood urea nitrogen (BUN) $35.7 \mathrm{mg} / \mathrm{dl}$, creatinine $1.34 \mathrm{mg} / \mathrm{dl}, \mathrm{Ca} 7.2 \mathrm{mg} / \mathrm{dl}$, lactate dehydrogenase (LDH) $715 \mathrm{IU} / \mathrm{l}$, total protein $5.7 \mathrm{~g} / \mathrm{dl}, \mathrm{C}-$ reactive protein (CRP) $29.4 \mathrm{mg} / \mathrm{dl}$, and $\mathrm{PaO}_{2} 53.6 \mathrm{mmHg}$ under room air. Abdominal computed tomography (CT) revealed a swollen pancreas with edema in the surrounding areas, cholelithiasis and the common duct stones, and ascites, and the patient was thus classified to be Grade IV (Fig. 1). From these findings, he was diagnosed as having severe acute pancreatitis according to the 1990 revised criteria for grading the severity of acute pancreatitis established by the Research Committee for Intractable Diseases of the Pancreas, Japanese Ministry of Health and Welfare. In spite of performing total parenteral nutrition and administering $500 \mathrm{mg} / \mathrm{day}$ of gabexate mesilate, his condition deteriorated. The hypoxemia worsened and the platelet count continued to decrease. He was then transferred to our hospital for further treatment on April 7, 1998.

On admission, his consciousness was disturbed and he suffered from delirium. His blood pressure was $146 / 76 \mathrm{mmHg}$, and his pulse was arrhythmic with a rate of $112 / \mathrm{min}$. His abdomen was markedly distended with diffuse tenderness and mild guarding, tympanic sounds on percussion, and decreased sounds on auscultation. The laboratory findings were as follows: white blood cell count $5,100 / \mu 1$, red blood cell count $423 \times 10^{4} / \mu \mathrm{l}$, hemoglobin $12.9 \mathrm{~g} / \mathrm{dl}$, platelet count $5.3 \times 10^{4} / \mu \mathrm{l}$, amylase 69 IU/l, BUN $15.4 \mathrm{mg} / \mathrm{dl}$, creatinine $0.7 \mathrm{mg} / \mathrm{dl}, \mathrm{Ca} 6.8 \mathrm{mg} / \mathrm{dl}$, Na $127 \mathrm{mEq} / l, \mathrm{~K} 3.7 \mathrm{mEq} / l, \mathrm{Cl} 93 \mathrm{mEq} / l$, aspartate aminotransferase $37 \mathrm{mU} / \mathrm{ml}$, alanine aminotransferase $21 \mathrm{mU} / \mathrm{ml}, \mathrm{LDH}$ $654 \mathrm{mU} / \mathrm{ml}$, total protein $5.5 \mathrm{~g} / \mathrm{dl}$, CRP $22.3 \mathrm{mg} / \mathrm{dl}$, and $\mathrm{PaO}_{2}$ $90.6 \mathrm{mmHg}$ under a reservoir mask at $6 \mathrm{l} / \mathrm{min}$. A chest radiographic examination revealed left pleural effusion and atelectasis in the left lower lung field.

In addition to $500 \mathrm{mg} /$ day of gabexate mesilate, the administration of $1,000 \mathrm{mg} /$ day of citicoline, 10,000 units/day of heparin sodium, 150 units/day of human anti-thrombin III, and

From the Department of Internal Medicine, *the Department of Pathology, Saga Prefectural Hospital Koseikan, Saga

Received for publication October 16, 1998; Accepted for publication October 23, 1999

Reprint requests should be addressed to Dr. Yoshikazu Umeno, the Department of Internal Medicine, Saga Prefectural Hospital Koseikan, 1-12-9 Mizugae, Saga 840-8571 


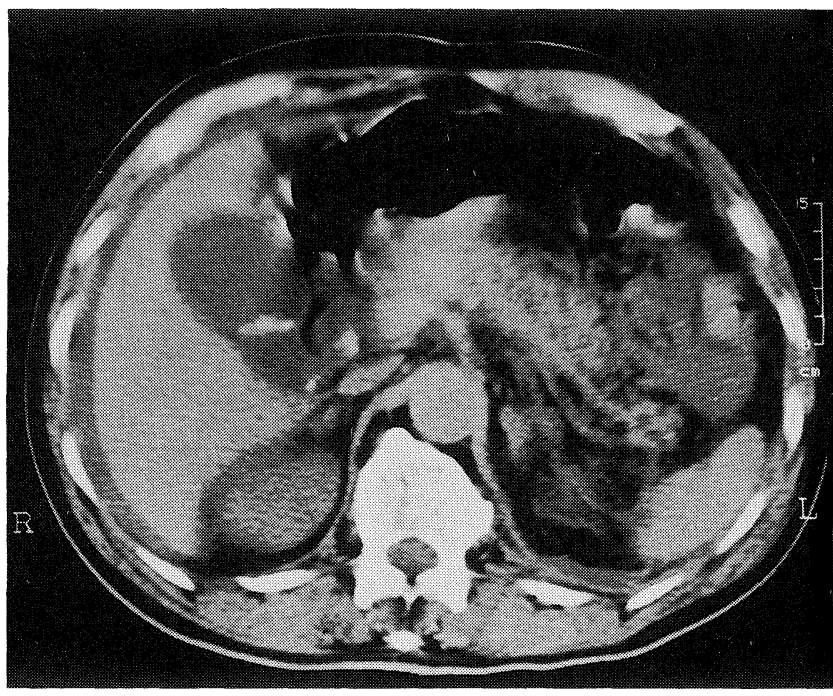

Figure 1. Abdominal computed tomography shows a diffusely enlarged pancreas and inflammatory changes in the surrounding tissue. Gallstones and ascites are also noted.

$2 \mathrm{~g} /$ day of piperacillin sodium was started. Continuous drainage was instituted for left pleural effusion. Following these treatments, the biochemical abnormalities began to improve gradually. On the 8th hospital day, $\mathrm{PaO}_{2}$ was $88.7 \mathrm{mmHg}$ under a nasal cannula at $2 \mathrm{l} / \mathrm{min}$, the number of platelets increased to $24.7 \times 10^{4} / \mu \mathrm{l}$, and the CRP decreased to $5.3 \mathrm{mg} / \mathrm{dl}$. Heparin sodium and gabexate mesilate were then discontinued on the 8th and 14th hospital day, respectively. The patient's overall condition also improved gradually, although low grade to middle grade fever persisted and he sometimes felt palpitation due to the rapid ventricular rate in atrial fibrillation. A liquid diet was started on the 37th hospital day. He was able to completely consume almost all meals and also felt a desire to defecate. However, he was not able to defecate for the first two days after starting the liquid diet. He had watery diarrhea on the 39th hospital day. Bloody stools were noted with abdominal pain on the 40th hospital day. The bloody stools persisted, and he died of hemorrhagic and hypovolemic shock on the 42nd hospital day, despite receiving such intensive care as transfusions, mechanical ventilation, and hemodialysis.

At autopsy, hemorrhagic necrosis of the colon was seen ranging from the terminal ileum to the right tranverse colon and from the sigmoid to the rectum (Fig. 2). A histolopathological examination revealed evidence of ischemic damage with various degrees of infarction (Fig. 3). There was no evidence of ischemic damage in the remaining segment of the colon, and congestion was seen in the small intestine. The pancreas was characterized by edema, fatty necrosis, and interstital inflammation, but most of the pancreatic parenchema was well preserved. An abscess measuring $3 \times 1.5 \mathrm{~cm}$ in diameter was observed between the neck of the pancreas and the root of the superior mesenteric vein (SMV), and it extended to the SMV, where both vasculitis and thrombus formation were observed

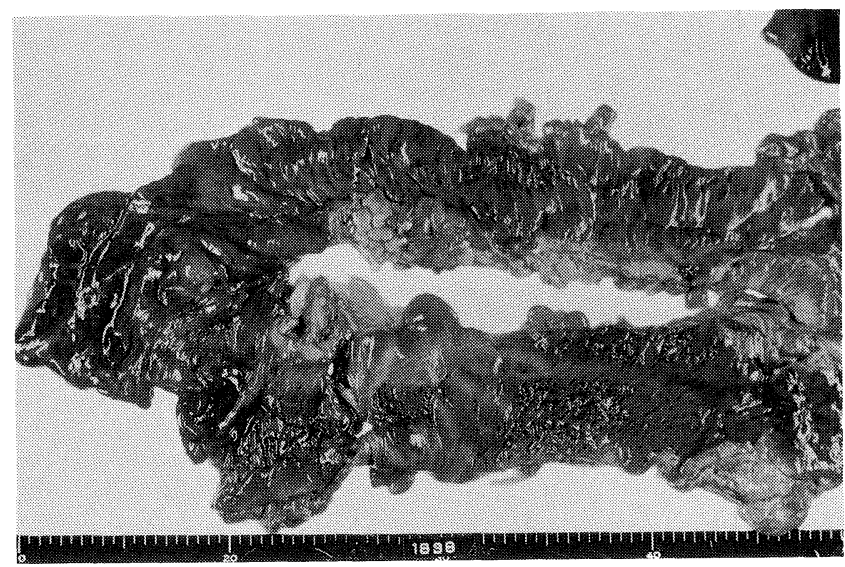

Figure 2. The mucosa of the ascending and right transverse colon demonstrates edema and marked hyperemia with patchy areas of the intact mucosa.

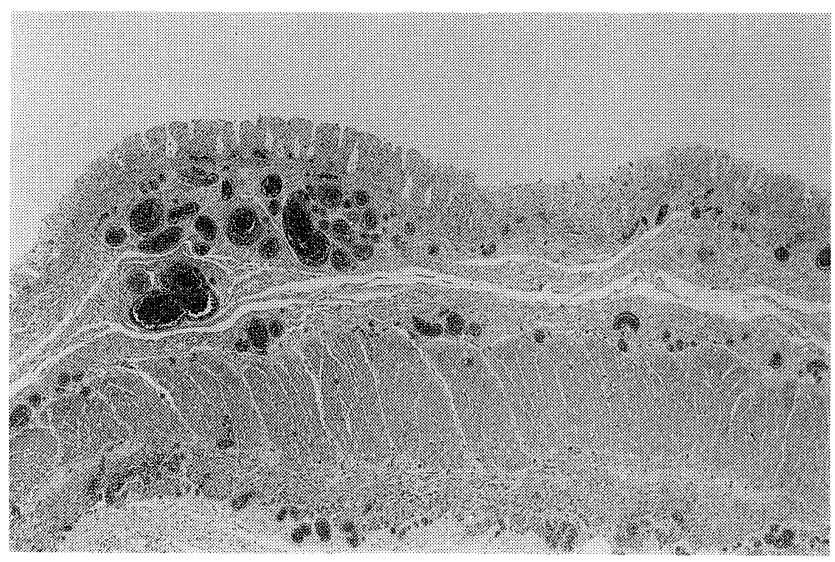

Figure 3. The mucosa and submucosa of the colon show coagulation necrosis, and the proper muscle layer is still intact. Vascular congestion is seen in the vessels from the mucosa to the subserosa (HE stain, $\times 8)$.

(Fig. 4). There was no thrombosis in either the splenic vein or the portal vein. No arterial embolus or thrombus was detected in the mesenteic arteries, and the heart was grossly normal except for the presence of ventricular hypertrophy.

\section{Discussion}

Ischemic bowel diseases are a heterogeneous group of disorders that have as their unifying feature hypoxia of the small and/or large intestine which is caused by alterations in the blood flow. Clinical manifestations vary depending on such anatomic factors as the site of ischemia, the nature of the occlusive process, collateral circulation, superimposed vascular spasm, and the degree and duration of ischemic insult (6).

Pancreatitis is one of the conditions associated with colonic 


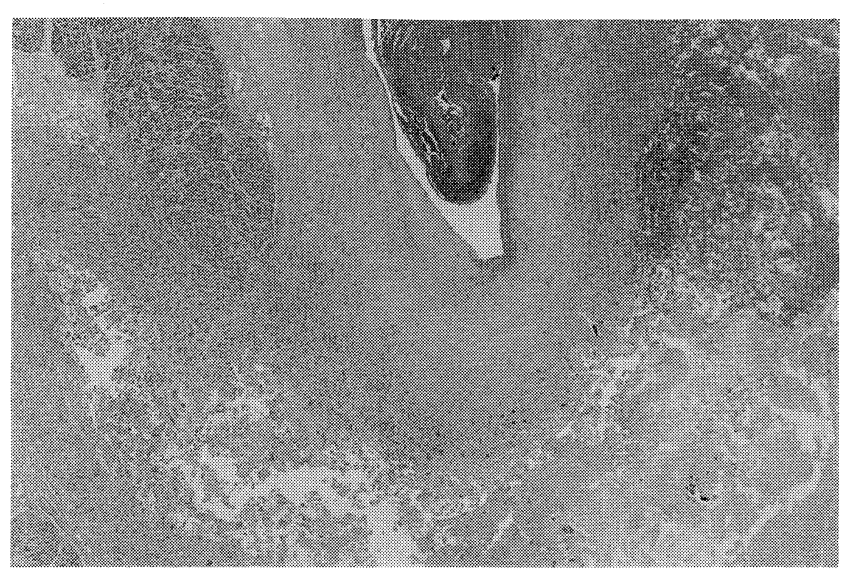

A

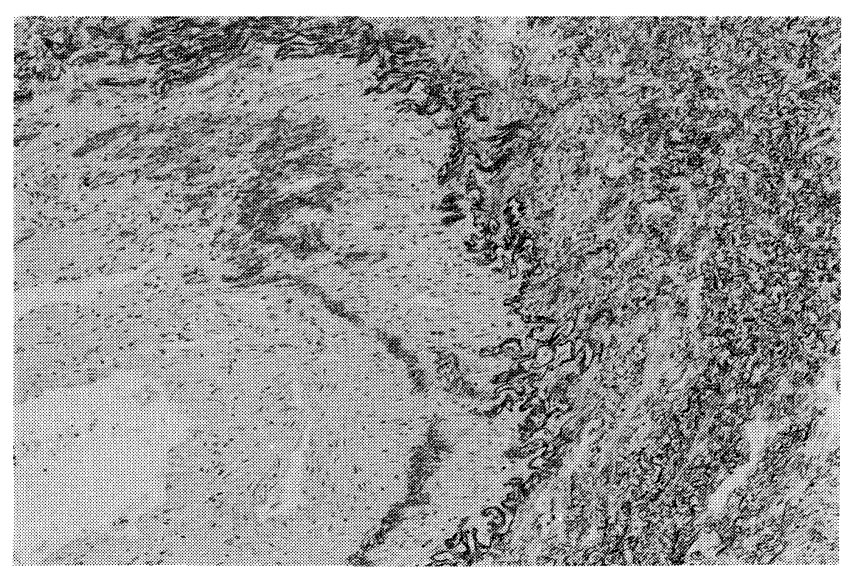

B

Figure 4. A) An abscess containing necrotic debris is present around the neck of the pancreas where the root of the superior mesenteric vein (SMV) is occluded by intraluminal thrombus (HE stain, $\times 5$ ). B) Weigert's elastin stain shows the venous thrombus has narrowed the lumen of the SMV $(\times 50)$.

complications, although colonic involvement as a consequence of pancreatitis is uncommon $(7,8)$. The colonic lesions associated with acute pancreatitis are divided into the following three groups from a pathological point of view: (a) A mesocolic mass secondary to necrosis of the fatty tissue resulting in external inflammatory compression. (b) Pericolitis showing lesions mainly in the serosa and subserosa, in which both the pancreatic enzymes and peripancreatic inflammation have extended directly through the mesentery. (c) Ischemic changes in the mucosa, submucosa, and tunica muscularis, which develop into colonic necrosis and/or perforation in severe cases. Its pathogenesis is considered to be due to congestion of the blood flow as a result of compression induced by severe edema in the mesentery, thrombus formation in the mesenteric and submucosal vessels, disseminated intravascular coagulation, and a decreased blood pressure $(1,5)$.
In the present case, a complex thrombus mixed with fibrin and red cells, which is thought to be formed within a few days, was found in the SMV. Mesenteric venous thrombosis can have either a sudden acute onset, a subacute onset of weeks to months, or a chronic course, although it most often has a subacute course (9). The mortality rate in acute mesenteric venous thrombosis ranges from $20 \%$ to $50 \%$, which is significantly lower than the mortality in other forms of acute mesenteric vascular disease (10). A number of predisposing conditions have been associated with mesenteric venous thrombosis, including pancreatitis and other intraabdominal inflammatory conditions, hypercoagulable states, congestive heart failure, portal hypertension, and nonpenetrating abdominal trauma (9-12). The pathogenesis of mesenteric venous thrombosis in inflammatory disorders is probably related to the direct perivascular extension of the local inflammatory process, or the release of thrombogenic factors secondary to inflammation $(9,11,13$, 14). As a result, we believe that the SMV thrombosis observed in the present case was caused by acute pancreatitis probably resulting from gallstones and thereafter induced colonic necrosis.

Ischemic changes were seen in the colon from both the ascending to the right transverse colon and from the sigmoid to the rectum. The extent of the lesions conformed to the regions supplied by both the superior and inferior mesenteric artery. The extensive colonic necrosis was primarily attributable to the presence of mesenteric venous occlusion. However, such occurrence appeared to be too acute and the lesions too extensive for colonic necrosis secondary to SMV thrombosis.

The mesenteric blood flow might have decreased substantially due to an increase in the intraperitoneal pressure after the patient was put on a liquid diet. Moreover, propulsive movements occur in the colon after meals. They force a mass of feces into the rectum, and then the desire for defecation is felt. Intestinal distention and increased intraluminal pressure are thought to be responsible for colonic ischemia $(15,16)$. Our patient also had atrial fibrillation. Cardiac arrhythmia is one of the conditions that cause mesenteric vasoconstriction, is also referred to as nonocclusive mesenteric ischemia or poor mesenteric perfusion syndrome $(17,18)$. Based on the above described pathophysiological events, we therefore consider that acute nonocclusive ischemia may be superimposed on the SMV occlusion in the occurrence of colonic necrosis. The reason why the colon from the left transverse to the descending colon demonstrated no necrosis, is considered to be due to the fact that no thrombotic occlusion occurred in the inferior mesenteric vein.

\section{References}

1) Lukash WM. Complications of acute pancreatitis. Unusual sequelae in 100 cases. Arch Surg 94: 848-852, 1967.

2) Thompson WM, Kelvin FM, Rice RP. Inflammation and necrosis of the transverse colon secondary to pancreatitis. AJR Am J Roentgenol 128: 943-948, 1977.

3) Abcarian H, Eftaiha M, Kraft AR, Nyhus LM. Colonic complications of acute pancreatitis. Arch Surg 114: 995-1001, 1979. 


\section{UMENO et al}

4) Aldridge MC, Francis ND, Glazer G, Dudley HAF. Colonic complications of severe acute pancreatitis. Br J Surg 76: 362-367, 1989.

5) Bouillot JL, Alexandre JH, Vuong NP. Colonic involvement in acute necrotizing pancreatitis: results of surgical treatment. World J Surg 13: 8487, 1989.

6) Rogers AI, David S. Intestinal blood flow and diseases of vascular impairment. in: Gastroenterology. 5th ed. Haubrich WS, Schaffner F, Berk JE, Eds. W.B. Saunders Company, Philadelphia, 1995: 1212-1234.

7) Adams DB, Davis BR, Anderson MC. Colonic complications of pancreatitis. Am Surg 60: 44-49, 1994.

8) Gumaste VV, Gupta R, Wasserman D, Dave PB, Vieux U. Colonic involvement in acute pancreatitis. Am J Gastroenterol 90: 640-641, 1995.

9) Grendell JH, Ockner RK. Mesenteric venous thrombosis. Gastroenterology 82: 358-372, 1982.

10) Boley SJ, Kaleya RN, Brandt LJ. Mesenteric venous thrombosis. Surg Clin North Am 72: 183-201, 1992.

11) Font VE, Hermann RE, Longworth DL. Chronic mesenteric venous thrombosis: difficult diagnosis and therapy. Cleve Clin J Med 56: 823-828, 1989.
12) Stuart RC, Leahy AL, Cafferkey MT, Stephens RB. Superior mesenteric vein thrombosis caused by Yersinia pseudotuberculosis. Br J Surg 76: 272, 1989.

13) Chen CY, Lin $X Z$, Lin CY, et al. Colon involvement in acute pancreatitis. J Clin Gastroenterol 18: 243-245, 1994.

14) Cornu-Labat G, Kasirajan K, Simon R, Smith DJ, Herman ML, Rubin JR. Acute mesenteric vein thrombosis and pancreatitis. A rare association. Int J Pancreatol 21: 249-251, 1997.

15) Parodi J, Grisoni E, Ferrario C, Kramer A, Beven E. Hypertonicity of intestinal smooth muscle as a factor of intestinal ischemia in necrotizing enterocolitis. J Pediatr Surg 22: 713-718, 1987.

16) Wolf EL, Sprayregen S, Bakal CW. Radiology in intestinal ischemia. plain film, contrast, and other imaging studies. Surg Clin North Am 72: $107-$ 124, 1992.

17) Aldrete JS, Han SY, Laws HL, Kirklin JW. Intestinal infarction complicating low cardiac output states. Surg Gynecol Obstet 144: 371-375, 1977.

18) Boley SJ, Sprayregan S, Siegelman SS, Veith FJ. Initial results from an aggressive roentgenological and surgical approach to acute mesenteric ischemia. Surgery 82: 848-855, 1977. 